\title{
Low-latitude equinoctial spread-F occurrence at different longitude sectors under low solar activity
}

\author{
M. Pezzopane ${ }^{1}$, E. Zuccheretti ${ }^{1}$, P. Abadi ${ }^{2}$, A. J. de Abreu ${ }^{3}$, R. de Jesus ${ }^{3}$, P. R. Fagundes ${ }^{3}$, P. Supnithi ${ }^{4}$, \\ S. Rungraengwajiake ${ }^{4}$, T. Nagatsuma ${ }^{5}$, T. Tsugawa ${ }^{5}$, M. A. Cabrera ${ }^{6,7,8}$, and R. G. Ezquer ${ }^{7,8,9}$ \\ ${ }^{1}$ Istituto Nazionale di Geofisica e Vulcanologia, Rome, Italy \\ ${ }^{2}$ Division of Ionosphere and Telecommunication, Space Science Center, Indonesian National Institute of Aeronautics and \\ Space (LAPAN), Indonesia \\ ${ }^{3}$ Universidade do Vale do Paraíba, São José dos Campos, Brazil \\ ${ }^{4}$ Faculty of Engineering, King Mongkut's Institute of Technology Ladkrabang (KMITL), Bangkok 10520, Thailand \\ ${ }^{5}$ Space Weather and Environment Informatics Laboratory, National Institute of Information and Communications \\ Technology, Tokyo 184-8795, Japan \\ ${ }^{6}$ Laboratorio de Telecomunicaciones, DEEC, FACET, Universidad Nacional de Tucumán, Tucumán, Argentina \\ ${ }^{7}$ Laboratorio de Ionósfera, Departamento de Física, FACET, Universidad Nacional de Tucumán, Tucumán, Argentina \\ ${ }^{8}$ CIASUR, Facultad Regional Tucumán, Universidad Tecnológica Nacional, Tucumán, Argentina \\ ${ }^{9}$ Consejo Nacional de Investigaciones Científicas y Técnicas, Buenos Aires, Argentina
}

Correspondence to: M. Pezzopane (michael.pezzopane@ingv.it)

Received: 9 July 2012 - Revised: 17 December 2012 - Accepted: 21 December 2012 - Published: 5 February 2013

\begin{abstract}
We present the results of a comparative study of spread-F signatures over five low-latitude sites: Chiangmai $\left(\mathrm{CGM} ; 18.8^{\circ} \mathrm{N}, 98.9^{\circ} \mathrm{E}\right.$, mag. Lat. $\left.8.8^{\circ} \mathrm{N}\right)$, Thailand; Tanjungsari (TNJ; $6.9^{\circ} \mathrm{S}, 107.6^{\circ} \mathrm{E}$, mag. Lat. $16.9^{\circ} \mathrm{S}$ ), Indonesia; Palmas (PAL; $10.2^{\circ} \mathrm{S}, 311.8^{\circ} \mathrm{E}$, mag. Lat. $\left.0.9^{\circ} \mathrm{S}\right)$ and São José Dos Campos (SJC; $23.2^{\circ} \mathrm{S}, 314.1^{\circ} \mathrm{E}$, mag. Lat. 14.0 $0^{\circ} \mathrm{S}$ ), Brazil; and Tucumán (TUC; $26.9^{\circ} \mathrm{S}, 294.6^{\circ} \mathrm{E}$, mag. Lat. $\left.16.8^{\circ} \mathrm{S}\right)$, Argentina. The investigation was based on simultaneous ionograms recorded by an FMCW (frequencymodulated continuous-wave) at CGM, an IPS-71 (digital ionosonde from KEL aerospace) at TNJ, a CADI (Canadian Advanced Digital Ionosonde) at PAL and SJC, and an AIS-INGV (Advanced Ionospheric Sounder - Istituto Nazionale di Geofisica e Vulcanologia) at TUC, during the equinoctial periods March-April $\left(R_{12}=2.0\right.$ and $\left.R_{12}=2.2\right)$ and September-October $\left(R_{12}=6.1\right.$ and $\left.R_{12}=7.0\right) 2009$, for very low solar activity. Spread-F signatures were categorized into two types: the range spread-F (RSF) and the frequency spread-F (FSF). The study confirms that the dynamics and the physical processes responsible for these phenomena are actually complicated. In fact, the features that arise from the investigation are different, depending on both the longitude sector and on the hemisphere. For instance, TUC, un-
\end{abstract}

der the southern crest of the ionospheric equatorial ionization anomaly (EIA), shows a predominance of RSF signatures, while both SJC, under the southern crest of EIA but in a different longitude sector, and CGM, under the northern crest of EIA, show a predominance of FSF signatures. Moreover, the spread-F occurrence over the longitude sector that includes CGM and TNJ is significantly lower than the spread-F occurrence over the longitude sector of PAL, SJC, and TUC.

Keywords. Ionosphere (Equatorial ionosphere; Ionospheric irregularities; Wave propagation)

\section{Introduction}

Plasma irregularities and inhomogeneities in the equatorial F-region, which are caused by plasma instabilities, are responsible for the widespread trace both in range and in frequency that often characterizes the ionograms recorded at low latitudes. This phenomenon was first reported by Booker and Wells (1938) while investigating the ionograms recorded at Huancayo, Peru. The equatorial spread-F (ESF) usually occurs just after local sunset and the scale sizes of the 


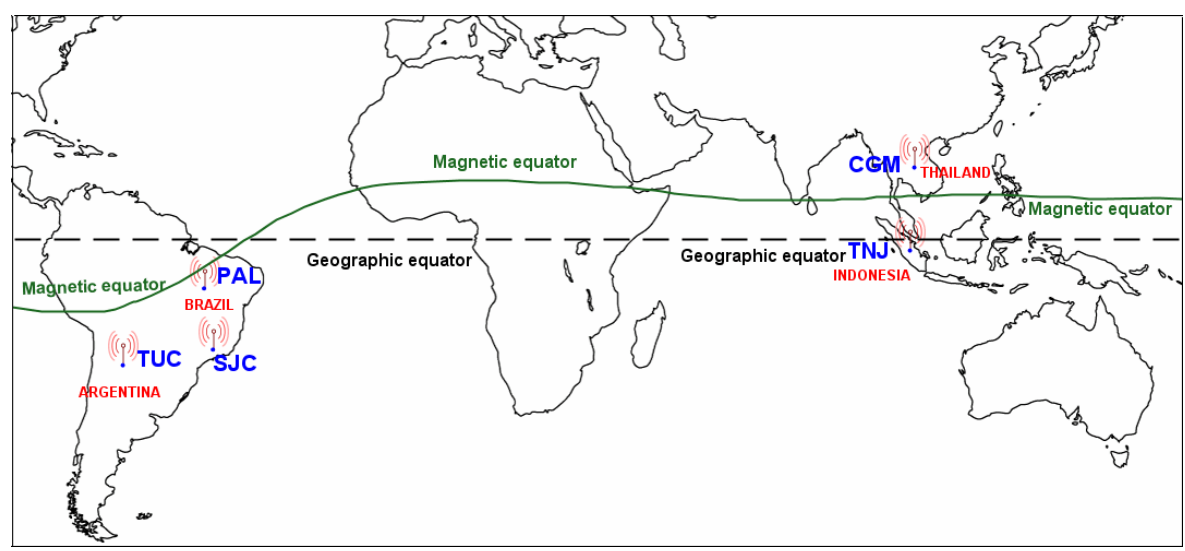

Fig. 1. Locations of the ionosondes used in the study.

irregularities responsible for the phenomenon, which can be studied and observed by different techniques, range from a few centimeters to a few hundred kilometers. At the magnetic equator, after sunset the F-region may rapidly rise and develop a steep bottomside gradient due to the combined effect of chemical recombination of the F- and E-regions and due to an actual increase in the vertical plasma velocity. These conditions result in an F-region plasma density profile which is shaped by the Rayleigh-Taylor (RT) instability (Ossakow, 1981). Other authors have stated that the basic mechanism of ESF onset is the RT instability in conjunction with the $\boldsymbol{E} \times \boldsymbol{B}$ drift instability (Abdu, 2001). In fact, in the post-sunset, the wind circulation, in the presence of an abrupt decay of the E-region conductivity and the quasi horizontal geomagnetic field, gives rise to a prereversal enhancement (PRE) in the evening zonal electric field, causing a significant $\boldsymbol{E} \times \boldsymbol{B}$ drift.

The occurrence of ESF varies with longitude, latitude, local time, season, and solar and geomagnetic activities (Kelley, 2009). One of the most interesting and challenging phenomenon is the regional characterization of the spread-F occurrence. It is known, in fact, that there is a clear longitudinal dependence of the spread-F occurrence, both at mid-latitudes and at equatorial regions, whose causes have not yet been clarified definitively (Abdu et al., 1992). Recently, several authors investigated the spread-F longitudinal differences. Hoang et al. (2010) performed a comparative study of the ESF characteristics over two equatorial sites, Ho Chi Minh in Vietnam and São Luis in Brazil, showing that the spread-F occurrence is significantly less frequent at Ho Chi Minh than at São Luis throughout the year. Huang et al. (2011) considered two Chinese stations, Changchun and Urumqi, at the same latitude and separate in longitude by 38 degrees, and they showed that the spread-F occurrence is always larger at Changchun than at Urumqi.

This paper describes a comparative study of spread-F occurrence over five low-latitude sites (Fig. 1): Chiangmai $\left(\mathrm{CGM} ; 18.8^{\circ} \mathrm{N}, 98.9^{\circ} \mathrm{E}\right.$, mag. Lat. $\left.8.8^{\circ} \mathrm{N}\right)$, Thailand; Tanjungsari (TNJ; $6.9^{\circ} \mathrm{S}, 107.6^{\circ} \mathrm{E}$, mag. Lat. $\left.16.9^{\circ} \mathrm{S}\right)$, Indone- sia; Palmas (PAL; $10.2^{\circ} \mathrm{S}, 311.8^{\circ} \mathrm{E}$, mag. Lat. $0.9^{\circ} \mathrm{S}$ ) and São José Dos Campos (SJC; $23.2^{\circ} \mathrm{S}, 314.1^{\circ} \mathrm{E}$, mag. Lat. $14.0^{\circ} \mathrm{S}$ ), Brazil; and Tucumán (TUC; $26.9^{\circ} \mathrm{S}, 294.6^{\circ} \mathrm{E}$, mag. Lat. $16.8^{\circ} \mathrm{S}$ ), Argentina. The periods considered, due to the simultaneous availability of ionograms in all the aforementioned stations, were those of March-April $2009\left(R_{12}=\right.$ 2.0 and $R_{12}=2.2$, respectively), where $R_{12}$ is the monthly smoothed sunspot number, and September-October 2009 ( $R_{12}=6.1$ and $R_{12}=7.0$, respectively), hence equinoctial months characterized by a very low solar activity. Several authors (e.g. Chandra and Rastogi, 1970; Rastogi, 1980; Abdu et al., 1985; Sahai et al., 2000; Pimenta et al., 2001; Bhaneja et al., 2009; Candido et al., 2011) have investigated the solar activity dependence of spread-F phenomenon and some of them have proved that spread-F occurrence and duration may show pronounced maxima near solar minimum. The magnetic activity characterizing the period under study is also low, as illustrated by Fig. 2, showing that $\sum \mathrm{Kp}$ (summation of the 3-hourly planetary $\mathrm{K}$ magnetic index, $\mathrm{Kp}$, along the whole day) is always lower than 24 , which is generally considered the threshold under which the magnetic conditions can be considered quiet.

This work represents one more contribution to study concurrently the ESF occurrence at sites located in different longitudinal sectors, and it confirms that the dynamics and the physical mechanisms responsible for this kind of phenomena are really complicated and difficult to be fully understood. The features that arise from the investigation are in fact different, depending both on the longitude sector and also on the hemisphere. Attention was also focused on the occurrence of satellite traces (ST). Satellite traces in the ionograms appear as one or more quasi replicas of the F-region trace at displaced virtual heights prior to the ESF onset, and are probably produced by oblique reflections from upwelling walls, that is, corrugations in the isodensity surfaces (Tsunoda, 2008). Our study seems to confirm that STs are precursors to the appearance of the range spread-F phenomenon on the ionogram trace. 


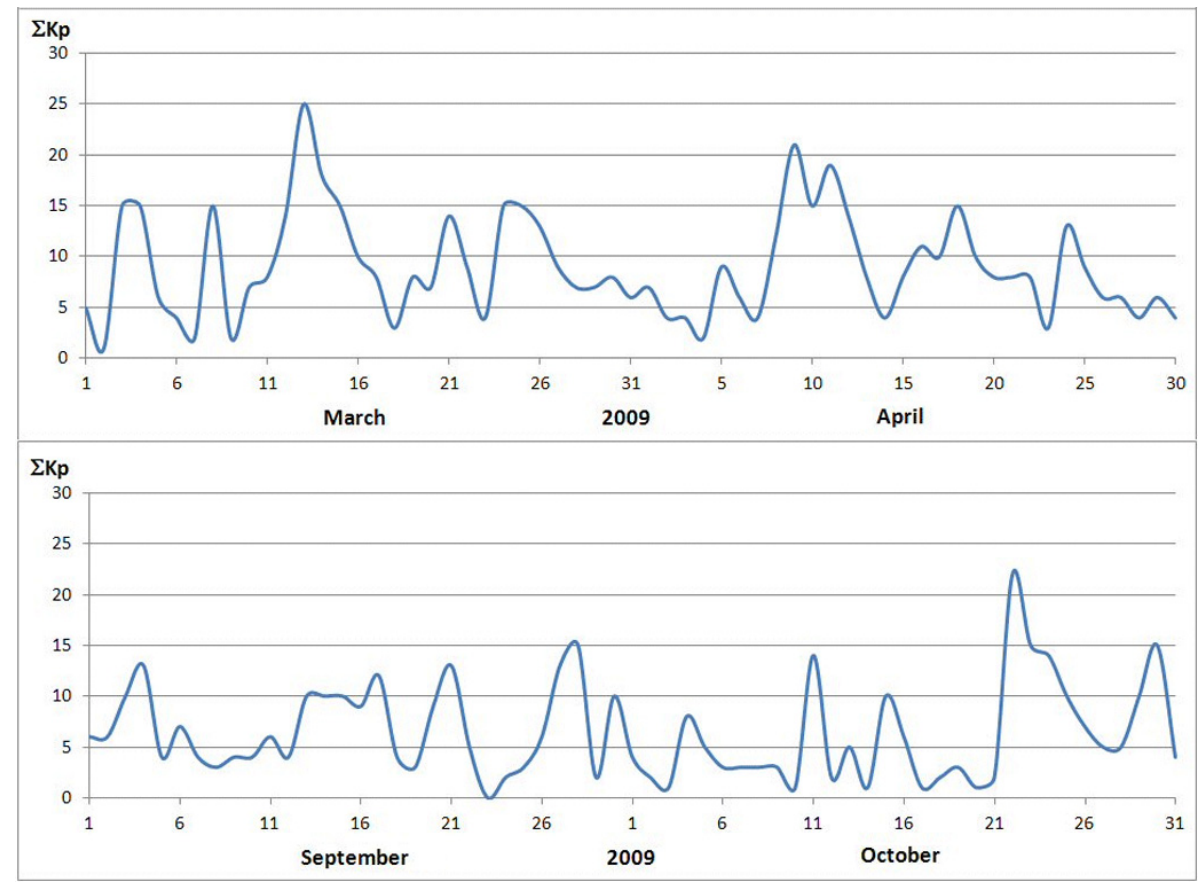

Fig. 2. Magnetic activity conditions in terms of $\sum K p$ for March, April, September, and October 2009.

\section{Analysis and results}

In order to perform the comparative study just mentioned at the end of the previous section, we considered simultaneous ionograms recorded by the following ionosondes: an FMCW (frequency-modulated continuous wave) at CGM, an IPS-71 (digital ionosonde from KEL aerospace) at TNJ, a CADI (Canadian Advanced Digital Ionosonde) (MacDougall et al., 1993) at PAL and SJC, and an AIS-INGV (Advanced Ionospheric Sounder - Istituto Nazionale di Geofisica e Vulcanologia) (Pezzopane et al., 2007) at TUC. The sounding repetition rate of all the ionosondes was set to $5 \mathrm{~min}$ except that of the IPS-71, which was set to $15 \mathrm{~min}$.

In our study, spread-F signatures were manually categorized into two types: the range spread-F (RSF) and the frequency spread-F (FSF). RSF signatures present echo spreading occurring mainly along the height axis and they are associated with plasma irregularities in the lower part of the F-region. FSF signatures present echo spreading along the frequency axis close to the critical frequencies of the ordinary and extraordinary traces of the ionograms, hence they are associated with irregularities nearby the F-region peak. Figures 3 and 4 show some examples of RSF, FSF, and STs recorded at each of the considered stations.

Equatorial spread-F phenomena were practically absent during daytime, and this is why we focused on the nighttime (18:00-06:00 Local Time (LT)) occurrence of both spread-F type and satellite traces. Figures 5, 6, 7, 8 and 9 show the results for all the five ionospheric stations we considered. Blue means FSF occurrence; red means RSF occurrence; green on the right of the vertical bar, representing the nighttime from 18:00 LT to 06:00 LT of each day of the month, means ST occurrence; cyan on the left of such a bar means occurrence of an E sporadic (Es) layer blanketing the upper ionospheric layers (except at TNJ, where it means only occurrence of a general Es layer not specifically blanketing); white means data unavailability; and black highlights days for which spread-F phenomena were not recorded.

The main features arising from the analysis are:

1. the highest spread-F occurrence was found at PAL in October. The lowest spread-F occurrence was found in March at SJC and CGM, just close to the southern and northern crests of the ionospheric equatorial ionization anomaly (EIA), respectively;

2. in general, the spread-F occurrence over the longitude sector that includes CGM and TNJ is significantly lower than the spread-F occurrence over the longitude sector of PAL, SJC, and TUC;

3. the RSF occurrence is predominant at TNJ and TUC, while the FSF occurrence is predominant at SJC and CGM. At PAL, RSF and FSF occurrences are somewhat balanced;

4. in particular, close to the southern anomaly crest, the RSF is predominant at TUC and TNJ, while the FSF is predominant at SJC;

5. spread-F phenomena between 18:00 LT and 21:00 LT occur mainly at PAL, close to the magnetic equator; 

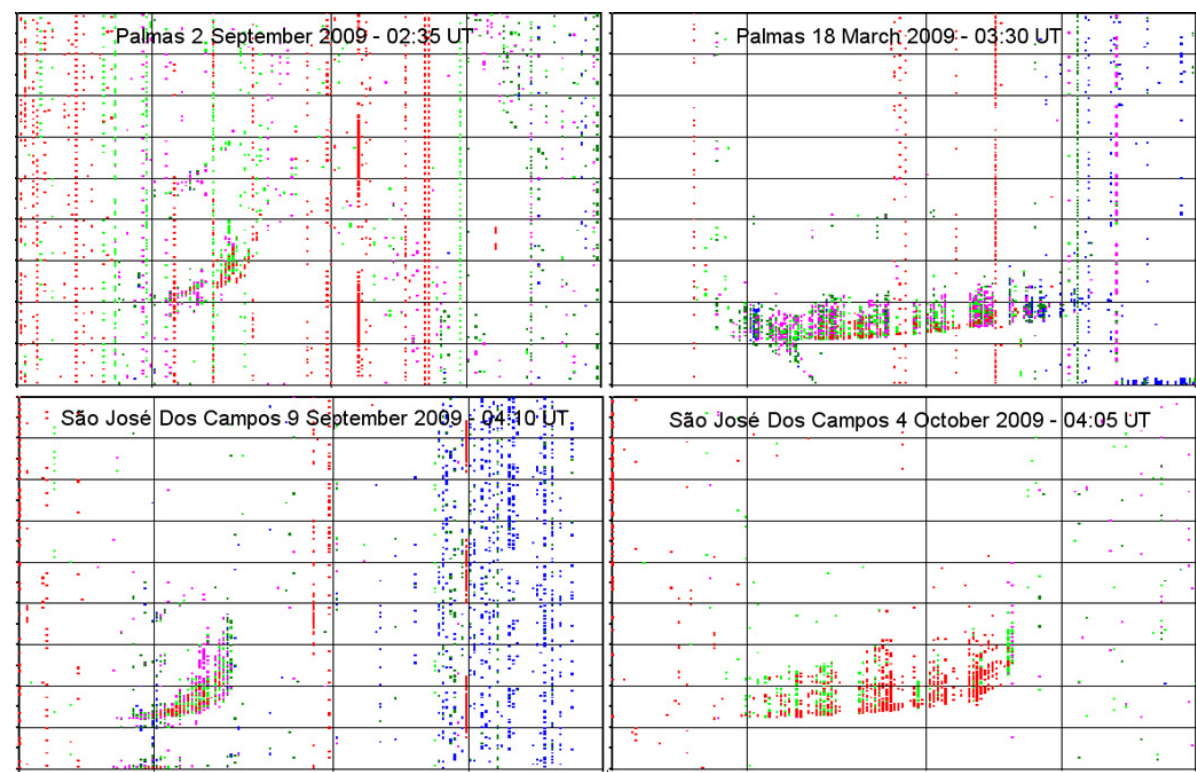

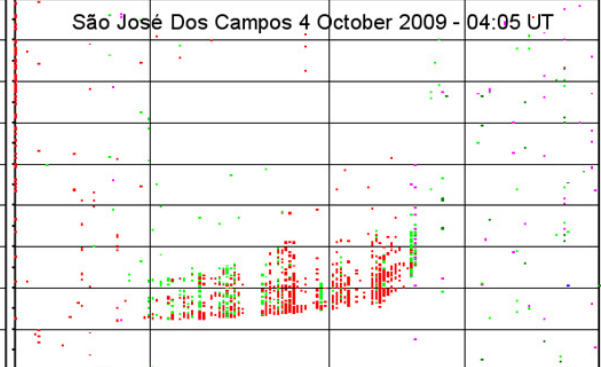
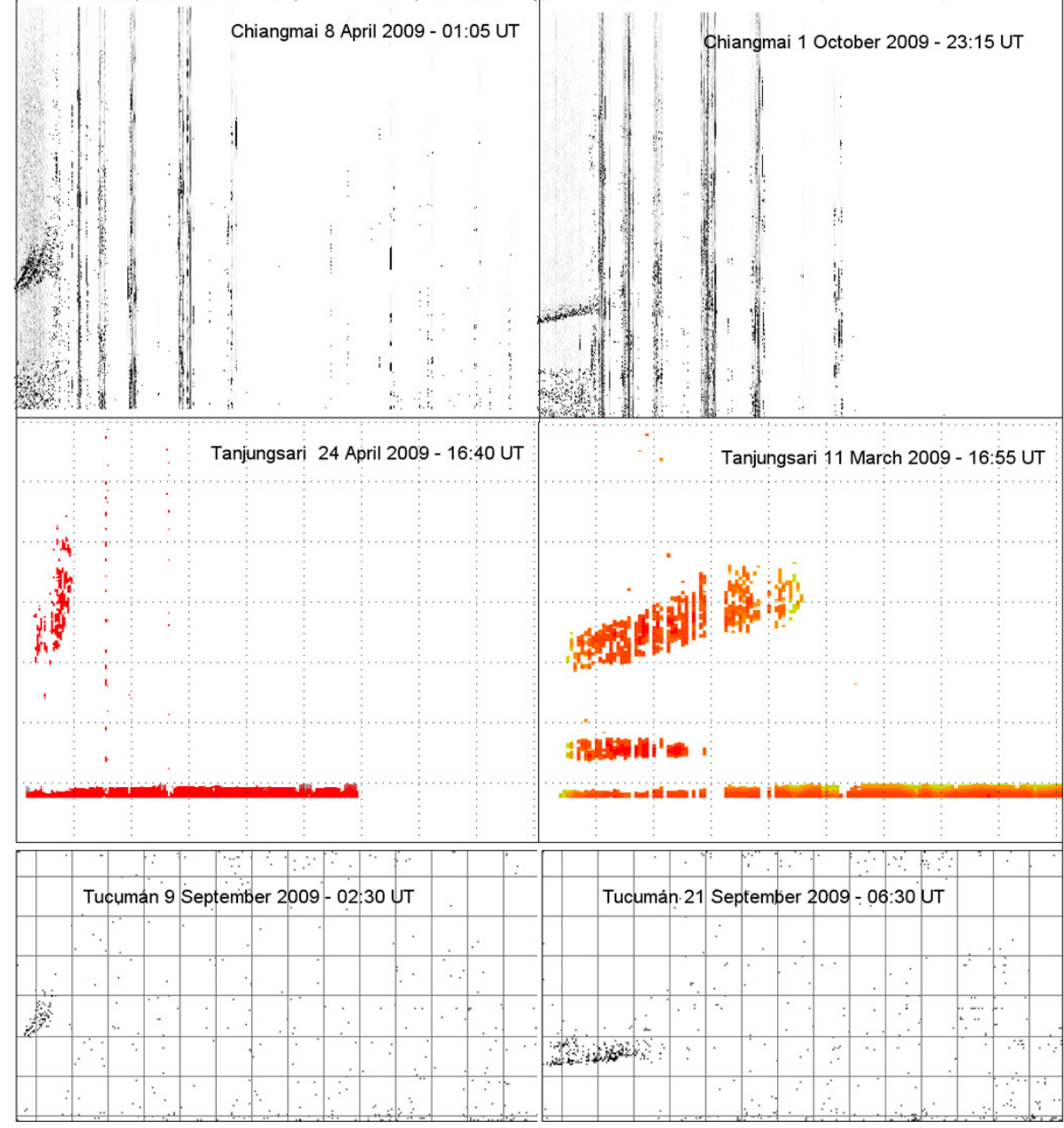

Fig. 3. Examples of FSF (in the left column) and RSF (in the right column) recorded at each of the ionospheric stations considered in the study. 


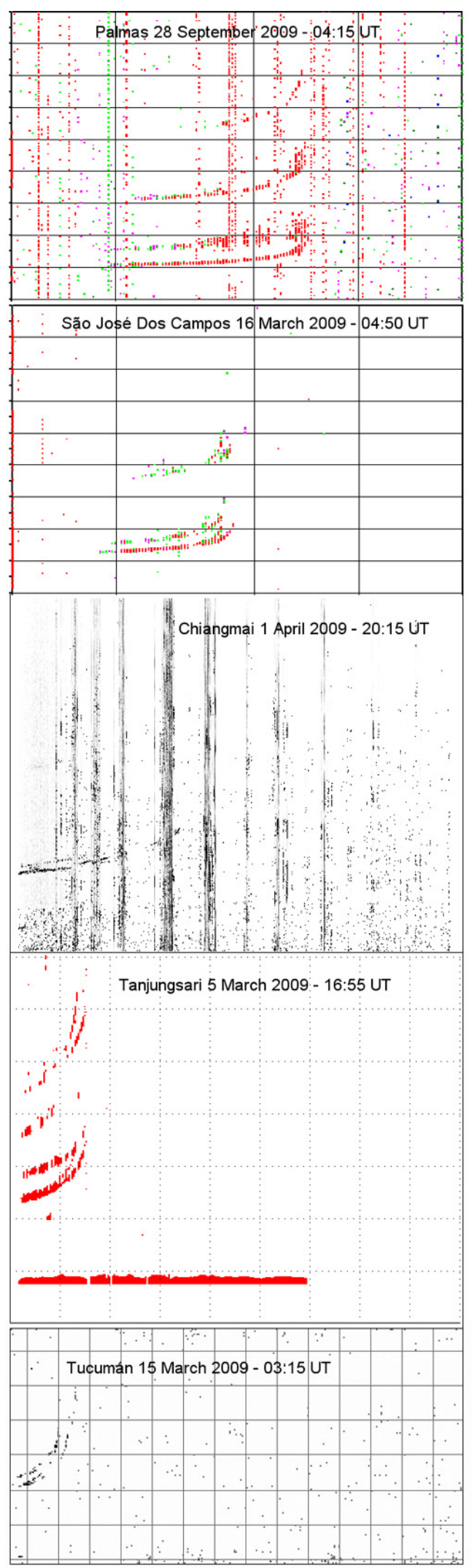

Fig. 4. Examples of satellite traces recorded at each of the ionospheric stations considered in the study.
6. at SJC spread-F signatures seem to disappear earlier than at any other station, mostly in March and in September;

7. the equinoctial asymmetry is visible at PAL, where the ESF occurrence is higher in October; at SJC and at TUC, where the ESF occurrence is (slightly at TUC) higher in September and in October; and at CGM, where the ESF occurrence is higher in March and in April. Considering that PAL, SJC, and TUC are located in the Southern Hemisphere, while CGM is located in the Northern Hemisphere, these equinoctial asymmetries consequently underline also an hemispherical asymmetry;

8. at TNJ, CGM and TUC, satellite traces are confirmed to be a necessary precursor to the appearance of an RSF trace on the ionograms;

9. the majority of no spread days is found at TNJ and CGM, even though it must be said that for those days most of the ionograms are characterized by blanketing Es layers.

\section{Discussion}

Figures 5-9 confirm one more time that the dynamics and the physical processes at the base of ESF phenomena are various and very complicated. The features that arise from our investigation are in fact different, depending both on the longitudinal sector and on the hemisphere.

Based on the presently known studies (e.g. Hoang et al., 2010, and references therein), the interconnected ionosphere-thermosphere system factors controlling the ESF development are (1) the evening F-region height and the vertical plasma drift due to the PRE that are controlled by the thermospheric zonal wind (eastward in the evening) and the gradient in the E-region conductivity near sunset, (2) the development of a sharp density gradient at the F-region bottomside where instabilities are triggered by seed perturbations widely believed to arise from gravity waves, and (3) the integrated Pedersen conductivity of the unstable flux tube, which is controlled by thermospheric meridional trans-equatorial winds. Concerning point (2), it is worth noting that Fagundes et al. (2009) and Bertoni et al. (2011) have recently shown that, in addition to gravity waves (GWs), also traveling planetary wave ionospheric disturbances (TPWIDs) play an important role in modulating the PRE and consequently the day-to-day ESF variability.

Many investigators (e.g. Sultan, 1996; Kelley, 2009) have proposed that the instability processes involving the RT and $\boldsymbol{E} \times \boldsymbol{B}$ instabilities could have started with irregularities in the bottomside F-region, giving rise to what is referenced as a bottomside spread-F (BSSF). The nonlinear development of these instabilities will then form the vertical elongated 

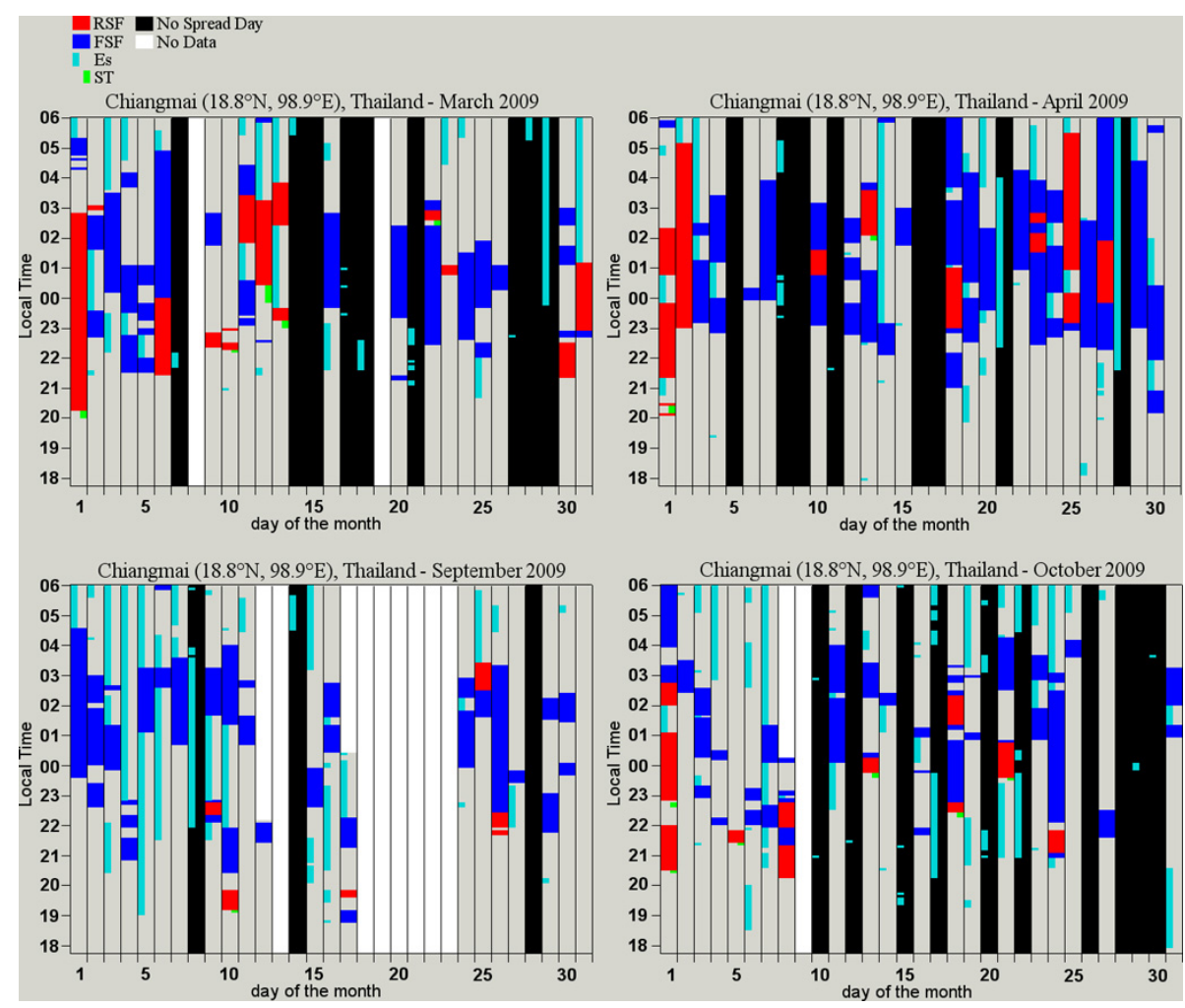

Fig. 5. RSF (red), FSF (blue), satellite trace (green), and blanketing Es layer (cyan) occurrences at Chiangmai, Thailand, from 18:00 LT to 06:00 LT, for March, April, September, and October 2009. White means data unavailability. Black highlights no spread-F days.

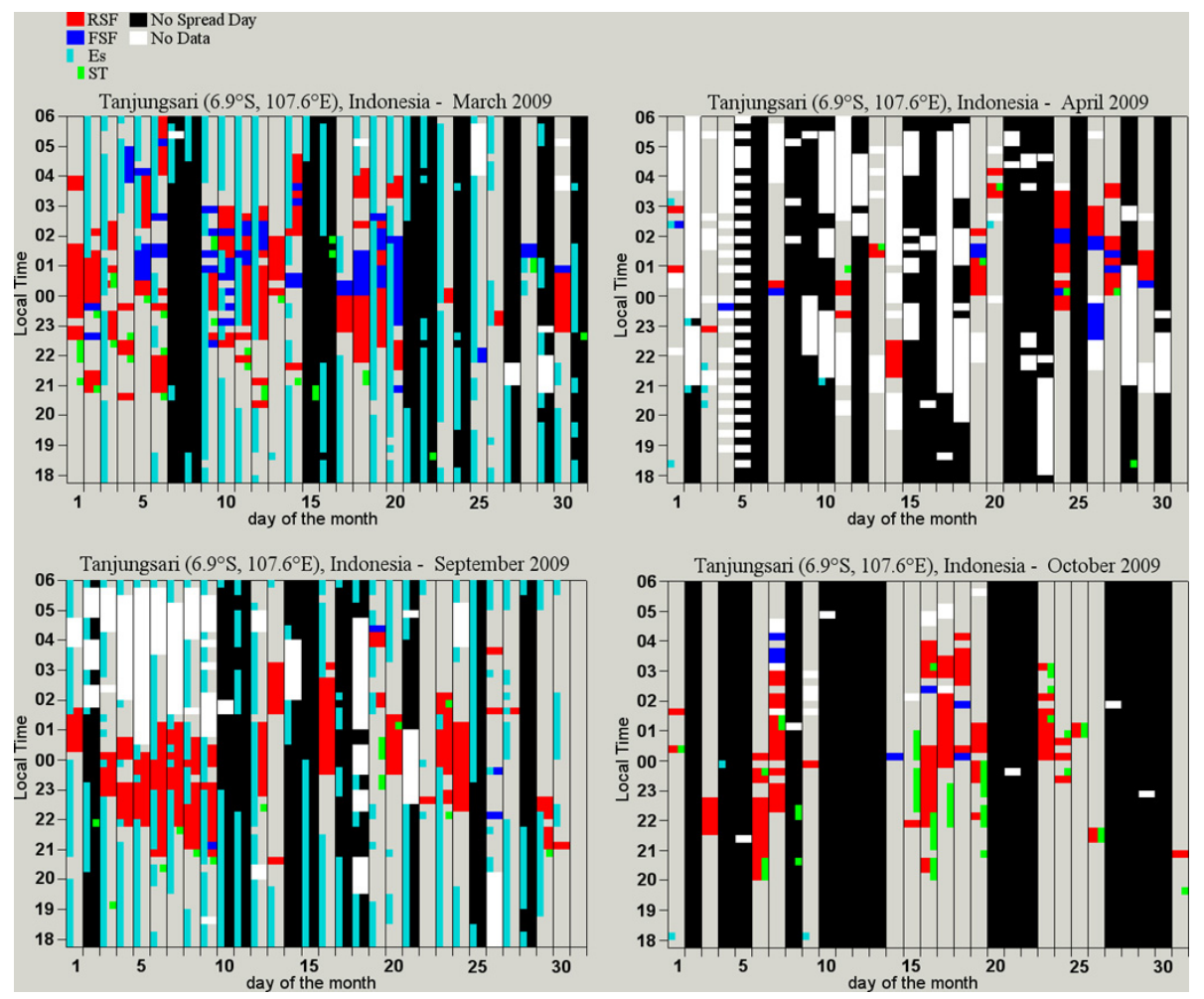

Fig. 6. Same as Fig. 5 for Tanjungsari, Indonesia. Cyan means presence of a general Es layer not specifically blanketing. 

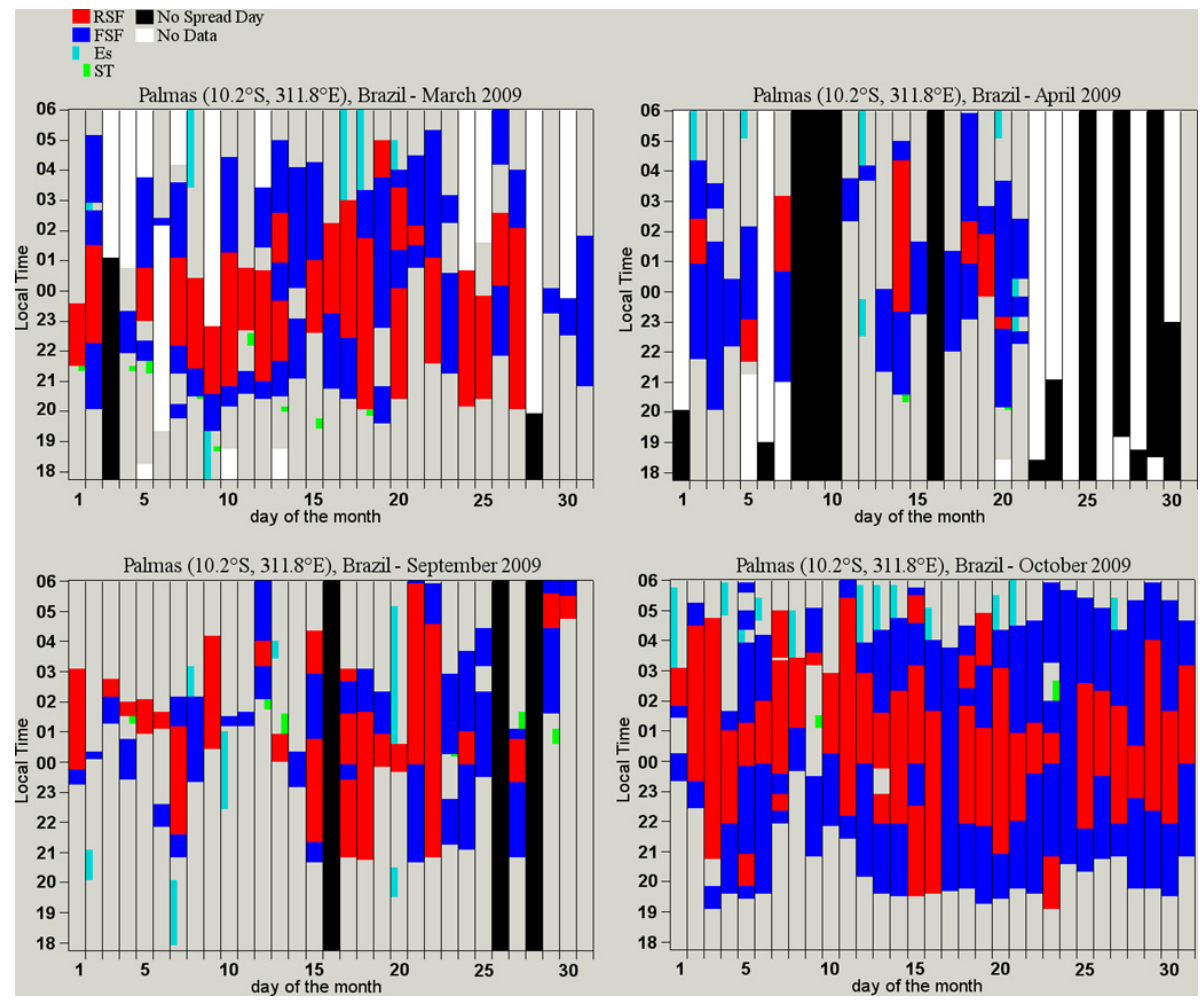

Fig. 7. Same as Fig. 5 for Palmas, Brazil.
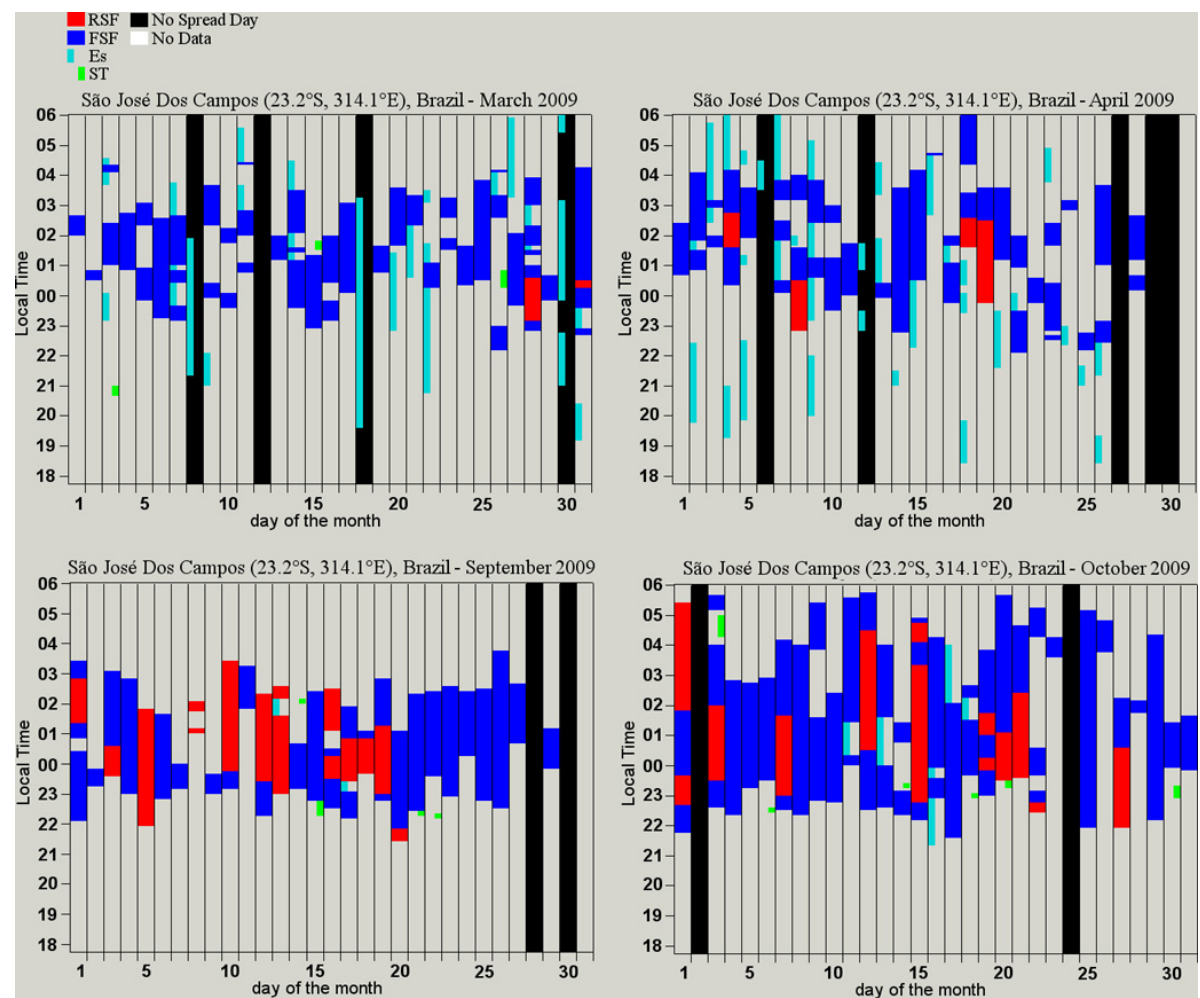

Fig. 8. Same as Fig. 5 for São José Dos Campos, Brazil. 


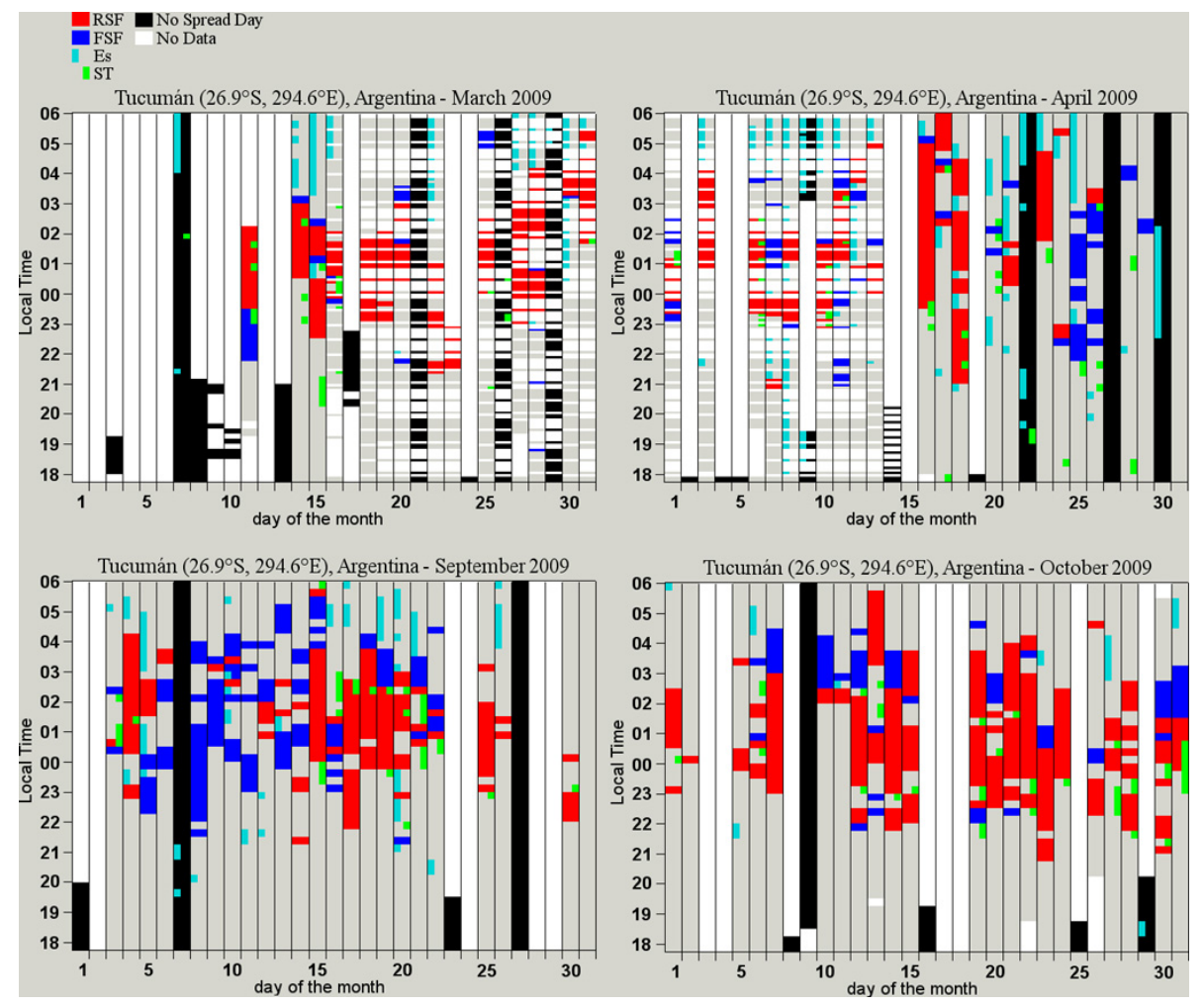

Fig. 9. Same as Fig. 5 for Tucumán, Argentina.

wedges of plasma depletions (bubbles) that drift upward from the bottomside F-region to altitudes as high as $1500 \mathrm{~km}$. According to several studies (e.g. Aarons, 1993; Whalen, 2002), the irregularities of the equatorial BSSF are usually confined below the F-region peak, and hence observable only by sounders near the magnetic equator. With regard to this, the highest ESF occurrence found at PAL matches with the fact that the magnetic equator represents the location where the creation of irregularities responsible for ESF phenomena is more probable. Moreover, the slight predominance of RSF at PAL confirms also the fact that irregularities are created mostly under the F-region peak.

These irregularities then move to both hemispheres along the magnetic field lines, and the FSF predominance characterizing SJC and CGM are probably the result of irregularities coming from the magnetic equator; this being proved also by the time of appearance of the spread-F signatures that is delayed with respect to the time of appearance of spread-F at the magnetic equator.

The case of TUC and TNJ, close to the southern peak of the equatorial ionization anomaly, in terms of spread-F type, is opposite to what was found for SJC and CGM. In fact, TUC and TNJ show a predominance of RSF signatures, suggesting that in this case the irregularities causing the ionogram spread signatures are also of different origin. Recently, Cabrera et al. (2010) showed that the RSF occurrence at TUC, heralded tens of minutes in advance by ST appear- ance, seems to be related to GWs propagating through the F-region that are triggered by the solar terminator. This concept is strengthened by our study that confirms that STs are a necessary precursor to the appearance of RSF signatures on the ionograms at TNJ and TUC (see Figs. 6 and 9). In fact, in these cases STs are due to corrugation in the isodensity surfaces caused by GW propagation which, in turn, can be considered to be the mechanism that, amplifying the post sunset seeding sources of irregularities (Fejer et al., 1999; Hysell and Burcham, 2002; Klausner et al., 2009), gives rise to the instabilities responsible for the RSF signatures occurring on the ionogram. On the other hand, under the southern crest of the EIA and for medium-low solar activity, also Fagundes et al. (2009) and Candido et al. (2011) have recently found evidence that spread-F events can be caused by ionospheric disturbances that are unrelated to equatorial processes, suggesting that traveling ionospheric disturbances and TPWIDs might be one of the main sources of these non-equatorial phenomena.

Concerning the equinoctial and hemispherical asymmetries, these might be attributed to trans-equatorial thermospheric winds and to differences in sunset times at ionospheric heights north and south of the magnetic equator.

The differences between the longitudinal sector that includes PAL, SJC, and TUC, and the longitudinal sector of CGM and TNJ, could be attributed to different PREs and hence to different F-region uplifts, as was already highlighted 
by Hoang et al. (2010). However, it is worthwhile to add that seasonal and longitudinal ESF variations can also be due to the effect of the magnetic declination angle, as was shown by Abdu et al. (1981) and Batista et al. (1986).

Finally, the majority of no spread days that is noticed at TNJ and CGM could be related to an ESF suppression phenomenon caused by meridional winds, which is more pronounced in the Thai-Indonesian sector (Abdu et al., 2006; Saito and Maruyama, 2006). Since previous studies (Sastri et al., 1997) have shown that the presence of a meridional wind does not suppress the spread-F in the presence of large PRE, this reinforces the idea that this sector is characterized by smaller sunset uplifts of the F-region than those characterizing the Brazilian/Argentinean sector.

\section{Conclusions}

We carried out a comparative study of RSF and FSF occurrences as observed by five low-latitude ionospheric stations widely separated both in longitude and latitude. The analysis focused on four equinoctial months: March, April, September, and October 2009, a year of very low solar activity.

The results of this comparison show that the spread-F occurrence at low latitudes is very different, depending both on the longitude and hemisphere.

In general, the spread-F occurrence characterizing the American longitude sector that includes PAL, SJC, and TUC, is higher than the spread-F occurrence characterizing the Asian longitude sector that includes CGM and TNJ. The issue is indeed enigmatic, mostly close to the southern anomaly crest, because TUC and TNJ are characterized by a predominance of RSF occurrence, while SJC on the contrary is characterized by a predominance of FSF occurrence.

We discussed these differences in terms of the PRE, the meridional winds and the gravity waves. In particular, this study confirms the fact that the RSF occurrence at TUC, anticipated by ST appearance, is most probably related to GWs propagating through the F-region rather than to equatorial processes.

It would be, however, interesting to verify whether the features emerging from this study are generalized. It is our intention to investigate further equinoctial ionogram datasets for medium and high solar activity by taking into account years following the one analyzed in this paper, and including more than five ionospheric stations, increasing consequently the considered longitude sectors.

Acknowledgements. Topical Editor K. Kauristie thanks H. Aveiro and one anonymous referee for their help in evaluating this paper.

\section{References}

Aarons, J.: The longitudinal morphology of equatorial F-layer irregularities relevant to their occurrence, Space Sci. Rev., 63, 209-
243, 1993.

Abdu, M. A.: Outstanding problems in the equatorial ionosphere thermosphere electrodynamics relevant to spread F, J. Atmos. Solar-Terr. Phys., 63, 869-884, 2001.

Abdu, M. A., Bittencourt, J. A., and Batista, I. S.: Magnetic declination control of the equatorial $F$ region dynamo field development and Spread-F, J. Geophys. Res., 86, 11443-11446, 1981.

Abdu, M. A., Sobral, J. H. A., Nelson, O. R., and Batista, I. S.: Solar cycle related range type spread-F occurrence characteristics over equatorial and low latitude stations in Brazil, J. Atmos. Terr. Phys., 47, 901-905, 1985.

Abdu, M. A., Batista, I. S., and Sobral, J. H. A.: A new aspect of magnetic declination control of equatorial spread $\mathrm{F}$ and F region dynamo, J. Geophys. Res., 97, 14897-14904, doi:10.1029/92JA00826, 1992.

Abdu, M. A., Iyer, K. N., de Medeiros, R. T., Batista, I. S., and Sobral, J. H. A.: Thermospheric meridional wind control of equatorial spread F and evening prereversal electric field, Geophys. Res. Lett., 33, L07106, doi:10.1029/2005GL024835, 2006.

Batista, I. S., Abdu, M. A., and Bittencourt, J. A.: Equatorial Fregion vertical plasma drifts: seasonal and longitudinal asymmetries in the American sector, J. Geophys. Res., 91, 12055-12064, 1986.

Bertoni, F. C. P., Sahai, Y., Raulin, J. P., Fagundes, P., Pillat, R. V. G., Gimenez de Castro, C. G. W., and Lima, L. C.: Equatorial spread-F occurrence observed at two near equatorial stations in the Brazilian sector and its occurrence modulated by planetary waves, J. Atmos. Solar-Terr. Phys., 73, 457-463, doi:10.1016/j.jastp.2010.10.017, 2011.

Bhaneja, P., Earle, G. D., Bishop, R. L., Bullett, T. W., Mabie, J., and Redmon, R.: A statistical study of midlatitude spread F at Wallops Island, Virginia, J. Geophys. Res., 114, A04301, doi:10.1029/2008JA013212, 2009.

Booker, H. G. and Wells, H. W.: Scattering of radio waves by the F-region of the ionosphere, J. Geophys. Res., 43, 249-256, 1938.

Cabrera, M. A., Pezzopane, M., Zuccheretti, E., and Ezquer, R. G.: Satellite traces, range spread-F occurrence, and gravity wave propagation at the southern anomaly crest, Ann. Geophys., 28, 1133-1140, doi:10.5194/angeo-28-1133-2010, 2010.

Candido, C. M. N., Batista, I. S., Becker-Guedes, F., Abdu, M. A., Sobral, J. H. A., and Takahashi, H.: Spread F occurrence over a southern anomaly crest location in Brazil during June solstice of solar minimum activity, J. Geophys. Res., 116, A06316, doi:10.1029/2010JA016374, 2011.

Chandra, H. and Rastogi, R. G.: Solar cycle and seasonal variation of spread-F near the magnetic equator, J. Atmos. Terr. Phys., 32, 439-443, 1970.

Fagundes, P. R., Abalde, J. R., Bittencourt, J. A., Sahai, Y., Francisco, R. G., Pillat, V. G., and Lima, W. L. C.: F layer postsunset height rise due to electric field prereversal enhancement: 2 . Traveling planetary wave ionospheric disturbances and their role on the generation of equatorial spread F, J. Geophys. Res., 114, A12322, doi:10.1029/2009JA014482, 2009.

Fejer, B. G., Scherliess, L., and de Paula, E. R.: Effects of the vertical plasma drift velocity on the generation and evolution of equatorial spread F, J. Geophys. Res., 104, 19859-19869, 1999.

Hoang, T. L., Abdu, M. A., MacDougall, J., and Batista, I. S.: Longitudinal differences in the equatorial spread $\mathrm{F}$ characteristics between Vietnam and Brazil, Adv. Space Res., 45, 351-360, 
doi:10.1016/j.asr.2009.08.019, 2010.

Huang, W. Q., Xiao, Z., Xiao, S. G., Zhang, D. H., Hao, Y. Q., and Suo, Y. C.: Case study of apparent longitudinal differences of spread F occurrence fort two midlatitude stations, Radio Sci., 46, RS1015, doi:10.1029/2009RS004327, 2011.

Hysell, D. L. and Burcham, J.: Long term studies of equatorial spread F using the JULIA radar at Jicamarca, J. Atmos. SolarTerr. Phys., 64, 1531-1543, 2002.

Kelley, M. C.: The Earth's Ionosphere: Plasma Physics and Electrodynamics, Int. Geophys. Ser., vol. 96, Elsevier Inc., pp. 556, 2009.

Klausner, V., Fagundes, P. R., Sahai, Y., Wrasse, C. M., Pillat, V. G., and Becker-Guedes, F.: Observations of GW/TID oscillations in the F2 layer at low latitude during high and low solar activity, geomagnetic quiet and disturbed periods, J. Geophys. Res., 114, A02313, doi:10.1029/2008JA013448, 2009.

MacDougall, J. W., Grant, I. F., and Shen, X.: The Canadian Advanced Digital Ionosonde: Design and Results, paper presented at 24th General Assembly of the International Union of Radio Science, Kyoto, Japan, 1993.

Ossakow, S. L.: Spread-F theories-A review, J. Atmos. Terr. Phys., 43, 437-452, 1981.

Pezzopane, M., Zuccheretti, E., Bianchi, C., Scotto, C., Zolesi, B., Cabrera, M. A., and Ezquer, R. G.: The new ionospheric station of Tucumán: First results, Ann. Geophys.-Italy, 50, 483-492, 2007.

Pimenta, A. A., Fagundes, P. R., Bittencourt, J. A., and Sahai, Y.: Relevant aspects of equatorial plasma bubbles under different solar activity conditions, Adv. Space Res., 27, 1213-1218, 2001.
Rastogi, R. G.: Seasonal and solar cycle variations of equatorial spread-F in the American zone, J. Atmos. Terr. Phys., 42, 593597, 1980.

Sahai, Y., Fagundes, P. R., and Bittencourt, J. A.: Transequatorial Fregion ionospheric plasma bubbles: solar cycle effects, J. Atmos. Solar-Terr. Phys., 62, 1377-1383, 2000.

Saito, S. and Maruyama, T.: Ionospheric height variations observed by ionosondes along magnetic meridian and plasma bubble onsets, Ann. Geophys., 24, 2991-2996, doi:10.5194/angeo24-2991-2006, 2006.

Sastri, J. H., Abdu, M. A., Batista, I. S., and Sobral, J. H. A.: Onset conditions of equatorial (range) spread F at Fortaleza, Brazil, during the June solstice, J. Geophys. Res., 102, 24013-24021, 1997.

Sultan, P. J.: Linear theory and modeling of the Rayleigh-Taylor instability leading to the occurrence of equatorial F, J. Geophys. Res., 101, 26875-26891, 1996.

Tsunoda, R. T.: Satellite traces: An ionogram signature for large scale wave structure and a precursor for equatorial spread F, Geophys. Res. Lett., 35, L20110, doi:10.1029/2008GL035706, 2008.

Whalen, J. A.: Dependence of the equatorial bubbles and bottomside spread $\mathrm{F}$ on season, geomagnetic activity and $\boldsymbol{E} \times \boldsymbol{B}$ drift velocity during solar maximum, J. Geophys. Res., 107, 1024, doi:10.1029/2001JA000039, 2002. 